\title{
Analysis of Clinical Features and Risk Factors of Death in Patients Admitted to Hospital with Acute Mushroom Poisoning: A Retrospective Analysis of 315 Cases
}

\author{
Wen Li, Wu Weihua, Zhaolan Yu, Li Li, Linwang Gan, Santao Ou* \\ Department of Nephrology, the Affiliated Hospital of Southwest Medical University, Luzhou, Sichuan, 646000, China
}

${ }^{*}$ Correspondence to: Santao Ou, Department of Nephrology, the Affiliated Hospital of Southwest Medical University, the 25th Taiping Street, Luzhou, Sichuan, 646000, China; Tel: +86-13679676835; Email: ousantao@163.com

Received: July 27, 2018; Accepted: August 08, 2018; Published: August 16, 2018;

\begin{abstract}
Aim: To review the clinical features and identify mortality risk factors of patients admitted to hospital for acute mushroom poisoning (AMP) .

Methods: We retrospectively analyzed a database of 315 patients who underwent acute mushroom poisoning between September 2003 and December 2017 at our hospital. The patients were divided into the survival group $(n=272)$ and death group $(n=43)$ based on the prognosis. Multivariate logistic regression was used to evaluate the risk factors associated with death.
\end{abstract}

Results: Overall, 315 cases were enrolled into the statistical analysis. The average age of them was $40.66 \pm 20.86$ years and there were 193 (61.27\%) male. Patients with latency of 6-24 hours had a higher rate of composition $(54.60 \%)$ and mortality $(11.75 \%)$. Liver was the most commonly involved organ $(152 / 523,29.06 \%)$ and patients with liver damage had the highest mortality $(40 / 315,12.70 \%)$. There was significant relationship between the number of organs involvement and mortality rate. Three or more organs damage could obviously increase mortality rate $(P<0.05)$. Compared with survival group, patients in death group had higher levels of alanine aminotransferase (ALT), total bilirubin direct (TBIL), direct bilirubin (DBIL) , prothrombin time (PT) , activated partial thrombin time (APTT), creatine kinase MB (CK-MB), myoglobin (Mb), lactate dehydrogenase (LDH) and lower levels of albumin $(\mathrm{ALB})$ and sodium $\left(\mathrm{Na}^{+}\right)(P<0.05)$. ALT $\geq 200 \mathrm{U} / \mathrm{L}, \mathrm{PT} \geq 20 \mathrm{~s}$ and $\mathrm{ALB} \leq 30 \mathrm{~g} / \mathrm{L}$ were identified as independent risk factors of the death in $\mathrm{AMP}(P<0.05)$.

Conclusion: We found that the number of organs involvement, ALT $\geq 200 \mathrm{U} / \mathrm{L}, \mathrm{PT} \geq 20 \mathrm{~s}$ and ALB $\leq 30 \mathrm{~g} / \mathrm{L}$ were significantly associated with mortality. Clinicians should be aware the dynamic changes in the above factors so that they can be detected early and treated as soon as possible.

Key words: acute mushroom poisoning; survival group; death group; clinical features; risk factors; multiple organ dysfunction syndrome; retrospective analysis

\section{Introduction}

Poisonous mushroom has many types, colors, sizes and morphologies. It is difficult to visually distinguish it from edible mushrooms. Therefore, AMP is a common phenomenon. Some poisonous mushrooms are rich in toxins, which are heat stable and not inactivated by cooking. The chemical structure of toxins is similar to the herbicides diquat and paraquat, they can lead to nausea, vomiting, abdominal pain, diarrhea and it can even make the disease progress rapidly and cause multiple organ dysfunction syndrome (MODS) to death ${ }^{[1,2]}$. Amanita poisoning has long been a worldwide problem, because it accounts for about $90 \%$ of fatality ${ }^{[3]}$. The lethal dose of a-amanitin is very low, only $0.1 \mathrm{mg} / \mathrm{kg}$, and some mushroom can contain up to $15 \mathrm{mg}$. That's one of the reasons why the mortality of $\alpha$-amanitin is high and it's known as the most poisonous toxins ${ }^{[4,5]}$. It had been reported that there were 50 to 100 deaths in Western European countries each year, and it was relatively rare in the United States, but there were also approximately 100 deaths in five years ${ }^{[6,7]}$. In China, the mortality of AMP is still high even as high as $21.2 \%$ and there are no special antidotes ${ }^{[8,9]}$. Although the disease has a high mortality rate, at present, most articles on AMP are case reports or series, and limited data exist on the clinical characteristics and possible mortality risk factors of patients admitted to hospital for AMP. To better identify the disease clinical features that are related to the fatal outcome of AMP patients admitted to hospital, we collected clinical data of 315 AMP patients admitted to our hospital from September 2003 to December 2017 and analyzed the clinical features and risk factors of the death, based on data from the initial admission.

\section{Materials and Methods}

\section{Participant enrollment and inclusion/exclusion criteria}

The patients who were diagnosed as AMP in our hospital between September 2003 and December 2017 were enrolled in the retrospective study. All these patients were included in the study according to the following inclusion: (1). They had a clear history of eating wild poisonous mushrooms and duration did not exceed three days. (2) .Co-fed persons had different symptoms of poisoning, while others had not. (3) . They all had relevant laboratory abnormalities. (4).Clinical datas were complete and successfully received follow-up for at least six months. The patients with history of related diseases including drugs of abuse, viral hepatitis, glomerulonephritis or other 
which could lead to liver, kidney and other organs damage were excluded from this study. This study strictly followed the ethical principles of human medical research in the Declaration of Helsinki and was approved by the hospital ethics committee and obtained the informed consent of all patients or their relatives.

\section{Diagnostic criterias for organs involvement}

The diagnostic criterias for organs involvement were as follows: (1). Elevated alanine aminotransferase ( $\geq 200 \mathrm{U} / \mathrm{L}$ ) six-fold greater than the upper limit of normal concentration (5 35 U/L), and/or the presence of total bilirubindirect ( $\geq 35 \mathrm{umol} / \mathrm{L}$ ) (normal range:0 27 umol/L), both of them were defined as liver damage. (2) Increased prothrombin time ( $\geq 20 \mathrm{~s}$ ) (normal range:0 14 s) and/or activated partial thrombin time ( $\geq 40 \mathrm{~s}$ ) (normal range:20 40 s) was considered to be coagulation abnormalities. (3). Elevated creatine kinase MB ( $\geq 5 \mathrm{ug} / \mathrm{ml}$ ) (normal range: $0.01-4.94 \mathrm{ng} / \mathrm{ml}$ ) was defined as heart involvement. (4). Increased creatinine ( $\geq 160 \mathrm{umol} / \mathrm{L}$ ) double than the normal concentration (normal range:45-84 umol/L) was considered to be kidney involvement. (5). The presence of relevant symptoms and/or signs (delirium, coma, twitch and irritability) was defined as damage to nervous system. (6). The appearance of abdominal signs and increased serum amelase ( $\geq 300 \mathrm{U} / \mathrm{L})$ three-fold greater than the upper limit of normal concentration (28-100 U/L), and/ or videography showed pancreatitis, both of them were defined as pancreas damage.

\section{Collection of clinical information}

The data we collected including gender, age, duration of hospitalization, latency period, laboratory indicators (including blood routine indexes, liver function indexes, renal function indexes, coagulation function indexes, myocardial injury markers, electrolytes indexes) and prognosis.

\section{Statistical analysis}

All statistical analyses were performed using SPSS version 22.0 for Windows (SPSS Corp, Chicago, IL, USA) . Kolmogorov-Smirnov test was used to test the normality of measurement data. Normal distribution data were expressed as the mean \pm standard deviation (SD) . Inter-group comparisons of continuous variables were performed by a 2 -sample t-test or $t^{\prime}$ test when the variance was uneven. While non-normal distribution of measurement data were described using median and interquartile range (IQR) values and rank sum test was used to compare the difference between the two groups. Frequencies and percentage were used to indicate categorical variables, and intergroup comparisons were performed by Chi-square test. To identify independent factors associated with death, explanatory items were selected using univariate analysis, followed by multivariate logistic regression. We considered $\mathrm{p}$ values less than 0.05 as statistically significant.

\section{Result}

\section{Baseline clinical features of all patients with acute mushroom poisoning}

During the study period, a total number of 315 patients were enrolled, including 272 (86.35\%) survival cases and 43 (13.65\%) death cases. Among all the patients, 193 (61.27\%) were male. The mean age was $40.66 \pm 20.86$ (range, 1 - 92) years. Table I shows the clinical baseline datas of all patients. The mean value of first recorded laboratory indexes were as follows: ALT 111.50 (26.1, 1087.40) U/L, TBIL $19.70(11.70,38.70)$ umol/L, ALB $44.90 \pm 7.39$ g/L, PT 14.20 $(12.70,19.40)$ seconds, APTT $35.00(30.20,45.00)$ seconds, CK-MB $1.54(0.52,3.71) \mathrm{ng} / \mathrm{m}, \mathrm{LDH} 340.20(211.40,875.80) \mathrm{U} / \mathrm{L}$ and $\mathrm{Na}^{+}$ $136.31 \pm 5.93 \mathrm{mmol} / \mathrm{L}$.

Poisonous mushroom' colors are varied. For the specific shapes of them, such as wearing "hat", waist "skirt", wearing "shoes", patients could not describe clearly. The intake amount was not equal, ranging from 20-500g. Regional distribution was significantly different, mostly in Sichuan, Yunnan and Guizhou province. Most patients were collective disease, while a small number of them was single.

\section{Multiple organ involvement of all the patients}

Liver (152 / 523, 29.06\%) was the most affected organs, followed by heart $(134 / 523,25.62 \%)$ and coagulation system (107 / 523, 20.46\%) (Figure. 1A) . The patients with liver damage had the highest mortality $(40 / 315,12.70 \%)$, then followed by coagulation disorders $(35 / 315,11.11 \%)$ and heart damage $(34 / 315,10.79 \%)$, respectively (Figure. 1B) . In addition, the more affected organs or systems, the higher mortality rate $(0.00 \%, 5.36 \%, 7.69 \%, 21.95 \%, 47.37 \%, 53.85 \%)$. The mortality of patients with four organs damage was higher than those who had three organs damage $(47.37 \%$ vs. $21.95 \%$; $\mathrm{P}<0.05)$, and the latter is higher than that of patients with two organs damage (21.95\% vs. $7.69 \%$; $\mathrm{P}<0.05)$ (Figure.1C) .

\section{Comparisons of clinical factors and outcomes in acute mushroom poisoning}

Late onset (latent period was 6-24 hours) (86.05\% vs. $49.63 \%$ ) was more common in death group and a total of 37 (11.75\%) patients became dead. According to data analysis, patients in death group had higher levels of ALT $(\mathrm{P}<0.001)$, TBIL $(\mathrm{P}=0.002)$, DBIL $(\mathrm{P}<0.001)$, $\mathrm{PT}(\mathrm{P}<0.001)$, APTT $(\mathrm{P}<0.001)$, CK-MB $(\mathrm{P}<0.001), \mathrm{Mb}(\mathrm{P}<$ $0.001), \mathrm{LDH}(\mathrm{P}<0.001)$ and lower levels of ALB $(\mathrm{P}=0.001)$ and $\mathrm{Na}^{+}(\mathrm{P}<0.001)$. Table I summarizes the patients'clinical data and outcomes of AMP.

\section{Risk assessment of clinical features associated with the death of acute mushroom poisoning patients}

Univariate logistic regression indicated that whether or not to adjust related confounding factors (age, gender and latency),WBC $\geq 12 \times 10^{9} / \mathrm{L}, \mathrm{ALT} \geq 200 \mathrm{U} / \mathrm{L}, \mathrm{TBIL} \geq 35 \mathrm{umol} / \mathrm{l}, \mathrm{DBIL} \geq 20 \mathrm{umol} / \mathrm{l}$, $\mathrm{ALB} \leq 30 \mathrm{~g} / \mathrm{L}, \mathrm{PT} \geq 20 \mathrm{~s}, \mathrm{APTT} \geq 40 \mathrm{~s}, \mathrm{CK}-\mathrm{MB} \geq 5 \mu \mathrm{g} / \mathrm{L}, \mathrm{MB} \geq 140 \mu \mathrm{g} / \mathrm{L}$, $\mathrm{LDH} \geq 500 \mathrm{U} / \mathrm{L}$ and $\mathrm{Na}+\leq 135 \mathrm{mmol} / \mathrm{L}$ were signifcantly associated with death in AMP (Table II). The above indicators were all included in the multivariate regression analysis, results showed that only ALT $\geq 200 \mathrm{U} / \mathrm{L}(\mathrm{OR}=4.50,95 \% \mathrm{CI}: 1.01-20.10, \mathrm{P}=0.049), \mathrm{PT} \geq 20 \mathrm{~s}(\mathrm{OR}$ $=6.14,95 \% \mathrm{CI}: 1.61-23.41, \mathrm{P}=0.008)$ and $\mathrm{ALB} \leq 30 \mathrm{~g} / \mathrm{L}(\mathrm{OR}=5.78$, 95\%CI:1.05-31.98, $\mathrm{P}=0.044)$ were identified as independent risk factors for death. Among them $\mathrm{PT} \geq 20$ s had the highest lethal risk and increased the risk of death by 5.14 times. 


\section{A Composition ratio of organ damage}

B

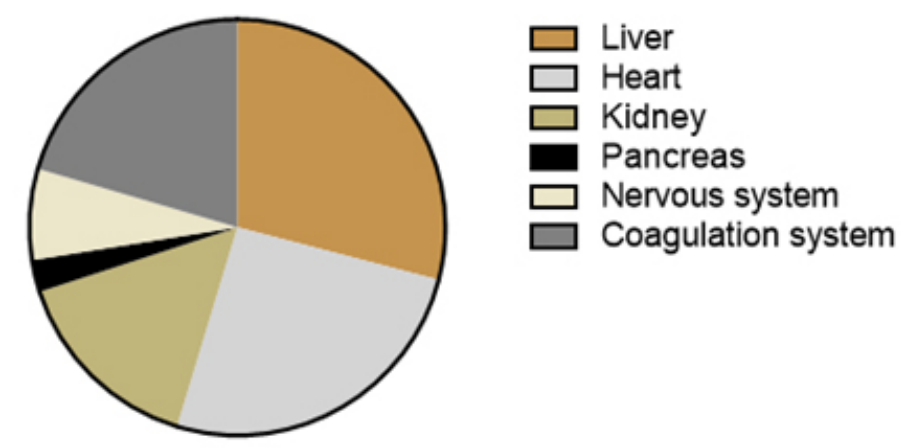

Comparison of organ damage in patients with different prognosis

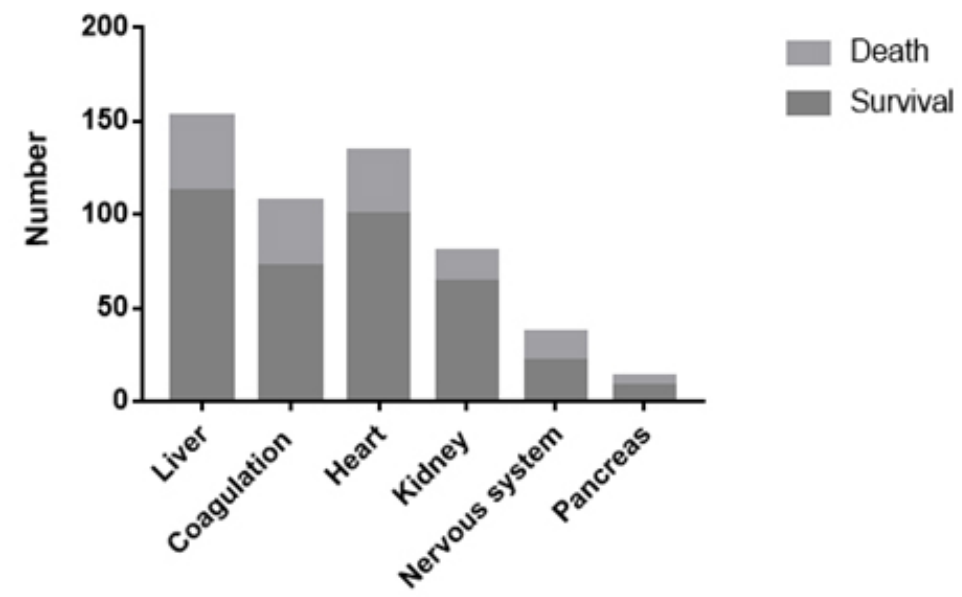

C

Different types of organ damage

\section{Relationship between organ damage} and mortality

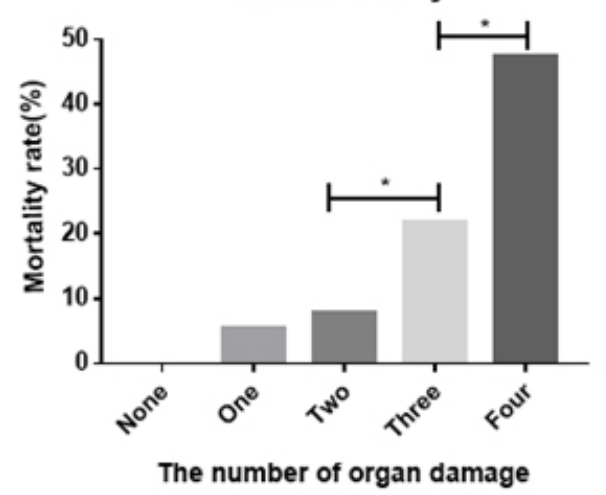

Figure 1. (A) Composition ratio of organ damage in patients with acute mushroom poisoning. They were $29.06 \%, 25.62 \%, 20.46 \%, 15.68 \%, 7.07 \%, 2.49 \%$, respectively.

(B) The comparison of organ damage in patients with different prognosis.

(C) Relationship between organ damage and mortality rate. The number of organs damage from one to four, mortality rates were $0.00 \%, 5.36 \%, 7.69 \%, 21.95 \%, 47.37 \%$. $* \mathrm{P}<0.05$ was considered statistically significant. 
Santao Ou (2018) Analysis of Clinical Features and Risk Factors of Death in Patients Admitted to Hospital with Acute Mushroom Poisoning:

A Retrospective Analysis of 315 Cases

Table I. The clinical baseline datas of 315 patients with acute mushroom poisoning

\begin{tabular}{|c|c|c|c|c|}
\hline Parameters & Total $(n=315)$ & Survival $(n=272)$ & Death $(n=43)$ & P value \\
\hline Male, $n(\%)$ & $193(61.27 \%)$ & $163(59.93 \%)$ & $30(69.77 \%)$ & 0.218 \\
\hline Age, years & $40.66 \pm 20.86$ & $40.46 \pm 20.16$ & $41.95 \pm 25.04$ & 0.710 \\
\hline Latent period, n (\%) & & & & $<0.001$ \\
\hline$<6$ hours & $125(39.68 \%)$ & $120(44.12 \%)$ & $5(11.63 \%)$ & \\
\hline 6-24 hours & $172(54.60 \%)$ & $135(49.63 \%)$ & $37(86.05 \%)$ & \\
\hline$>24$ hours & $18(5.71 \%)$ & $17(6.25 \%)$ & $1(2.33 \%)$ & \\
\hline White blood cell $\left(\times 10^{9} / \mathrm{L}\right)$ & $11.56 \pm 5.77$ & $11.03 \pm 5.24$ & $14.81 \pm 7.43$ & 0.002 \\
\hline Red blood cell $\left(\times 10^{12} / \mathrm{L}\right)$ & $4.81 \pm 0.79$ & $4.78 \pm 0.79$ & $5.04 \pm 0.69$ & 0.043 \\
\hline Alanine transaminas $(\mathrm{U} / \mathrm{L})$ & $111.50(26.1,1087.40)$ & $67.20(23.60,796.98)$ & $\begin{array}{c}1383.00 \\
(342.10,2691.50)\end{array}$ & $<0.001$ \\
\hline Total bilirubin (umol/L) & $19.70(11.70,38.70)$ & $17.35(10.98,32.78)$ & $48.20(22.50,75.10)$ & 0.002 \\
\hline Direct bilirubin (umol/L) & $7.0(3.9,21.00)$ & $6.20(3.70,13.18)$ & $36.00(14.10,56.70)$ & $<0.001$ \\
\hline Albumin $(\mathrm{g} / \mathrm{L})$ & $44.90 \pm 7.39$ & $45.10 \pm 22.56$ & $40.82 \pm 7.98$ & 0.001 \\
\hline Prothrombin time (s) & $14.20(12.70,19.40)$ & $13.85(12.50,17.00)$ & $28.20(17.40,67.80)$ & $<0.001$ \\
\hline Activated partial thrombin time (s) & $35.00(30.20,45.00)$ & $34.20(29.13,39.78)$ & $57.30(41.00,76.30)$ & $<0.001$ \\
\hline Creatine kinase-MB (ng/ml) & $1.54(0.52,3.71)$ & $1.24(0.45,3.02)$ & $3.71(1.48,15.32)$ & $<0.001$ \\
\hline Myoglobin (ng/ml) & $69.22(39.44,181.36)$ & $62.83(37.99,157.30)$ & $163.00(77.22,982.09)$ & $<0.001$ \\
\hline Lactate dehydrogenase (U/L) & $340.20(211.40,875.80)$ & $289.15(203.25,609.63)$ & $\begin{array}{c}1083.70 \\
(492.60,2987.80)\end{array}$ & $<0.001$ \\
\hline Sodium $(\mathrm{mmol} / \mathrm{L})$ & $136.31 \pm 5.93$ & $136.88 \pm 5.58$ & $132.76 \pm 6.85$ & $<0.001$ \\
\hline
\end{tabular}

Table II. The risk factors of death in acute mushroom poisoning analyzed by univariate logistic regression

\begin{tabular}{|c|c|c|c|c|c|c|}
\hline \multirow[t]{2}{*}{ Parameters } & \multicolumn{2}{|c|}{ Occurrence rate No. (\%) } & \multirow{2}{*}{$\begin{array}{l}\text { Unadjusted } \\
\qquad \mathrm{OR}[95 \% \mathrm{CI}]\end{array}$} & \multirow[t]{2}{*}{$P^{a}$ value } & \multirow{2}{*}{$\begin{array}{l}\text { Adjusted } \\
\qquad \mathrm{OR}[95 \% \mathrm{CI}]\end{array}$} & \multirow[t]{2}{*}{$\mathrm{P}^{\mathrm{b}}$ value } \\
\hline & Survival $(\mathrm{n}=272)$ & Death $(n=43)$ & & & & \\
\hline Age $\geq 16$ years & $221(81.25 \%)$ & $32(74.42 \%)$ & $0.67(0.32-1.42)$ & 0.295 & & \\
\hline Male (n/\%) & $193(61.27 \%)$ & $163(59.93 \%)$ & $0.65(0.32-1.30)$ & 0.218 & & \\
\hline Latent period $\geq 6 \mathrm{~h}$ & $152(55.88 \%)$ & $38(88.37 \%)$ & $6.00(2.29-15.71)$ & $<0.001$ & & \\
\hline White blood cell $\geq 12 \times 10^{9} / \mathrm{L}$ & $84(30.88 \%)$ & $25(58.13 \%)$ & $3.11(1.61-6.00)$ & $<0.001$ & $2.88(1.46-5.70)$ & 0.002 \\
\hline Red blood celll $\geq 5 \times 10^{12} / \mathrm{L}$ ) & $109(40.07 \%)$ & $26(60.46 \%)$ & $2.29(1.19-4.42)$ & 0.012 & $2.03(0.99-4.16)$ & 0.054 \\
\hline Alanine transaminas $\geq 200 \mathrm{U} / \mathrm{L}$ & $103(37.86 \%)$ & $40(93.02 \%)$ & $21.88(6.60-72.53)$ & $<0.001$ & $11.65(3.95-34.35)$ & $<0.001$ \\
\hline Total bilirubin $\geq 35 \mathrm{umol} / \mathrm{L}$ & $62(22.79 \%)$ & $29(67.44 \%)$ & $7.02(3.49-11.10)$ & $<0.001$ & $5.26(2.57-10.80)$ & $<0.001$ \\
\hline Direct bilirubin $\geq 20 \mathrm{umol} / \mathrm{L}$ & $66(24.26 \%)$ & $33(76.74 \%)$ & $10.30(4.82-22.02)$ & $<0.001$ & $6.17(2.98-12.78)$ & $<0.001$ \\
\hline Albumin $\leq 30 \mathrm{~g} / \mathrm{L}$ & $7(2.57 \%)$ & $5(11.62 \%)$ & $4.98(1.51-16.49)$ & 0.004 & $5.18(1.46-18.43)$ & 0.011 \\
\hline Prothrombin time $\geq 20 \mathrm{~s}$ & $43(15.80 \%)$ & $29(67.44 \%)$ & $11.03(5.39-22.58)$ & $<0.001$ & $15.81(6.80-36.73)$ & $<0.001$ \\
\hline Activated partial thrombin time $\geq 40$ s & $38(13.97 \%)$ & $29(67.44 \%)$ & $12.76(6.18-26.31)$ & $<0.001$ & $9.07(4.04-20.37)$ & $<0.001$ \\
\hline Creatine kinase-MB $\geq 5 \mathrm{ng} / \mathrm{ml}$ & $37(13.60 \%)$ & $20(46.51 \%)$ & $5.52(2.76-11.04)$ & $<0.001$ & $4.26(2.05-8.84)$ & $<0.001$ \\
\hline Myoglobin $\geq 140 \mathrm{ng} / \mathrm{ml}$ & $73(26.83 \%)$ & $23(53.48 \%)$ & $3.14(1.63-6.04)$ & $<0.001$ & $2.14(1.08-4.23)$ & 0.029 \\
\hline Lactate dehydrogenase $\geq 500 \mathrm{U} / \mathrm{L}$ & $78(28.67 \%)$ & $32(74.41 \%)$ & $7.24(3.47-15.07)$ & $<0.001$ & $5.60(2.64-11.88)$ & $<0.001$ \\
\hline Sodium $\leq 135 \mathrm{mmol} / \mathrm{L}$ ) & $74(27.20 \%)$ & $26(60.46 \%)$ & $4.09(2.10-7.97)$ & $<0.001$ & $3.17(1.59-6.34)$ & 0.001 \\
\hline
\end{tabular}

Abbreviatoins: OR, odds ratio; CI, confidence interval;

${ }^{a}$ Univariate analyses (Continuity correction $\chi 2$ test) were performed to evaluate the risk factors associated with death. Unadjustment of age, gender and latent period, $\mathrm{P}<0.05$ is considered statistically significant.

${ }^{\mathrm{b}}$ Adjustment of age, gender and latent period, $\mathrm{P}<0.05$ is considered statistically significant. 
Table III. The independent risk factors of death in acute mushroom poisoning analyzed by multivariate logistic regression

\begin{tabular}{|c|c|c|c|c|c|c|c|}
\hline & B & S.E. & Wald & $\operatorname{Exp}(B)$ & \multicolumn{2}{|c|}{ 95\% C.I } & P value \\
\hline Latent period $\geq 6 \mathrm{~h}$ & .95 & .56 & 2.81 & 2.57 & .85 & 7.78 & 0.094 \\
\hline Alanine transaminas $\geq 200 \mathrm{U} / \mathrm{L}$ & 1.50 & .76 & 3.88 & 4.50 & 1.01 & 20.10 & 0.049 \\
\hline Direct bilirubin $\geq 20 \mathrm{umol} / \mathrm{L}$ & .26 & .91 & .08 & 1.30 & .22 & 7.72 & 0.777 \\
\hline Albumin $\leq 30 \mathrm{~g} / \mathrm{L}$ & 1.76 & .87 & 4.04 & 5.78 & 1.05 & 31.98 & 0.044 \\
\hline Prothrombin time $\geq 20 \mathrm{~s}$ & 1.82 & .68 & 7.08 & 6.14 & 1.61 & 23.41 & 0.008 \\
\hline Lactate dehydrogenase $\geq 500 \mathrm{U} / \mathrm{L}$ & .19 & .54 & .13 & 1.21 & .42 & 3.48 & 0.724 \\
\hline Sodium $\leq 135 \mathrm{mmol} / \mathrm{L}$ ) & .49 & .43 & 1.28 & 1.63 & .70 & 3.80 & 0.259 \\
\hline
\end{tabular}

\section{Discussion}

Mushrooms are widely distributed in the world, their species are more than 5000, of which 50 to 100 species had been identified as toxic species, including more than 30 species could cause human death ${ }^{[10]}$. Mushroom poisoning mortality is up to $21.2 \%$ and this study described a mortality of $13.7 \%$, indicating that it has become one of the most important causes of death ${ }^{[1]}$. The prognosis of patients with AMP was very different, and may be influenced by many factors, such as the types of poisonous mushrooms, toxin dose, clinical phenotype, laboratory indexes, medical treatment and hemodialysis and so on ${ }^{[12,13]}$. Yilmaz et al. ${ }^{[14]}$ also suggested that white poison umbrella intake dose was closely related to the severity of the disease. Basing on the clinical characteristics of patients admitted to hospital for AMP, we mainly analyze the risk factors of death, to lay the foundation for guiding clinical treatment.

Different structures of poisonous mushrooms contain different concentrations of toxins, they can accumulate in different organs, making it difficult to detect in blood or urine $\left[14,{ }^{15]}\right.$, so, we can't accurately analyze poisonous mushrooms' species and toxins in our study. According to previous study, Cevik ea tl. ${ }^{[16]}$ reported that age was closely related to the mortality of mushroom poisoning and they thought organ function of the elderly gradually depletes, so that it was difficult to tolerate toxins to death. Schmutz et al. ${ }^{[17]}$ found that children who were younger than 6 years old were more prone to poisoning, but they did not specifically analyze the relationship between age and mortality. In our study, there were no significant differences in age between the two groups. The reason may be that we only compared the differences between children and adults and did not divide them more specifically. In terms of gender, Yardan et al. suggested that there were more women in the poisoning case than men, but some author described that males were more susceptible to toxins ${ }^{[7,18,19]}$. We also revealed that the ratio of male to female was 1.34: 1, however, gender differences have no effect on prognosis in AMP.
The clinical classification of mushroom poisoning varies greatly at home and abroad, and clinical types may overlap, there is still much controversy over the existence of hybrids. So far, there is no definitive guideline or consensus to define their classification accurately. Diza ea $t l^{[20]}$ divided it into three types: early onset ( $<6$ hours), late onset (6 24 hours) and delayed onset ( $>24$ hours). As already reported, latent period was crucial for the prognosis, but it was not a specific predictor $\left.{ }^{[21}, 22\right]$. In general, early-onset has the highest survival rate, but lateonset has the highest mortality rate, it can easily lead to liver and kidney failure ${ }^{[22}{ }^{23]}$. At the present study, we inferred that late onset had the highest incidence and mortality, based on it, we conducted univariate logistic regression analysis, showing that the incubation period which was greater than or equal to 6 hours was indeed one of the risk factors for toadstool poisoning to death. Clinicians should pay attention to such patients early and adequately.

Liver is the most important organ in patients with AMP, accounting for $29.06 \%$ in all organ or system involvement, this finding is consistent with previous literature ${ }^{[24]}$. The mortality of liver failure is relatively high, it was $12.70 \%$ in this study, however, past literature reported that it was as high as $50 \%$ to $90 \%{ }^{[25]}$. The reason may be that difference in evaluation criteria of liver damage can leads to difference in mortality, and widespread use of blood purification may effectively reduce mortality, but, so far, the most effective method to rescue liver failure is still liver transplantation ${ }^{[26]}$. Heart damage is also common, death group had high level of CK-MB, but it was within the normal range and logistic regression analysis showed that it had no effect on prognosis. The possible reason is that the effect of poisonous mushrooms on the cardiovascular system was mainly reflected in the abnormal electrocardiogram and blood pressure, as Ali ${ }^{[27]}$ said. So the markers of myocardial injury are often normal and not a risk factor for death.

In our study, most patients have more than two organs or systems damage. Therefore, we hypothesized that there was a link between 
the number of organs damage and mortality rate. Finally, the results confirmed that the number of organs damage from one to four, the mortality were $5.36 \%, 7.69 \%, 21.95 \%, 47.37 \%$. A small number of patients have five or six organs damage, so the mortality has not been counted. Three or more organs damage could obviously increase mortality rate, thus, early assessment of organ damage by clinicians has a positive effect on guiding clinical outcomes.

For the analysis of risk factors of experimental indicators, first of all, we compared the level of each index of two groups and select the index of difference statistically, excluding some of the error caused by unpredictable factors and selecting an appropriate range for logistic regression analysis, respectively. Because ALT mainly exists in the cytoplasm of hepatocytes and can be more sensitive to the damage of liver function and combined with changes in coagulation parameters, we found that when the ALT was less than $200 \mathrm{U} / \mathrm{L}$, the changes of PT and APTT were not obvious. While it was more than $200 \mathrm{U} / \mathrm{L}$, the changes of all of them were almost the same. Therefore, ALT $\geq 200$ $\mathrm{U} / \mathrm{L}$ for prognosis of AMP patients have a very important guiding significance. In our study, ALT in death group was significantly higher than survival group, 143 (45.40\%) patients had the ALT of more than $200 \mathrm{U} / \mathrm{L}$, including 103 (37.86\%) cases in survival group and $40(93.02 \%)$ cases in death group. The multivariate logistic regression analysis showed ALT $\geq 200 \mathrm{U} / \mathrm{L}$ was the independent risk factors of the death in AMP. However, Bita et al. ${ }^{[28]}$ suggested that even though ALT increased to more than 10 times of normal limits, it played no role in prognosis. The hepatotoxicity mechanism may be that metabolite of toxins, not the toxins, can binds to hepatocyte DNA-dependent RNA polymerase II and terminates intracellular protein synthesis, ultimately leading to cell death and releasing ALT ${ }^{[29,30,31]}$. Therefore, in order to prevent the occurrence of the risk factors of death, we can start from the mechanism to study the treatment.

Liver is a major site for the synthesis of many clotting factors in the human body and hepatic damage can be associated with irreversible coagulation abnormalities ${ }^{[32]}$. In our study, 107 (33.97\%) patients had coagulation disorders, with prolonged PT and APTT, which was consistent with the conclusion that Trabulus et al. and Bita et al. proposed ${ }^{[28,33]}$. But not the same, they thought that both of them were closely related to death, however, we only confirmed that PT $\geq 20$ s was independently associated with death in AMP. Also, liver plays an important role in the synthesis of albumin. Ahishali ea $t$ tl $^{[34]}$ found that toxins inhibit protein synthesis and cause hepatocyte necrosis, even lead to death. Our present study showed that albumin level in death group $(40.82 \pm 7.98 \mathrm{~g} / \mathrm{L})$ was lower than control group (45.10 $\pm 22.56 \mathrm{~g} / \mathrm{L})$ and it was an independent risk factor to death. As to the reason of low albumin, on the one hand, liver function may be severely damaged; On the other hand, gastrointestinal inflammation is more likely to cause intestinal congestion it and poor diet, resulting in malnutrition. For prevention, patients with AMP must not only be hepatopro tective but also need to strengthen nutritional support treatment.

\section{Limitation}

Some limitations of our study should be discussed. Firstly, as a retrospective study, we need to extract information from medical

records and some necessary data are not noted precisely, prone to selection bias. Secondly, poisonous mushrooms samples are difficult to collect and preserve and there's a lack of mushroom toxicology appraisal agencies. Therefore, we cannot analyze the influence of mushrooms type and prognosis. Thirdly, another challenging issue is difficulty in accurate determination of organs toxicity, so, in this study, self-defining analysis of the damage of various organs is conducted, which may also be one of the reasons leading to differences between the research conclusions and the past. Finally, our study is only a single center retrospective study, large-scale prospective studies can be carried out in the future to compare the prognosis of patients with high-risk and non-high-risk, so that the correlation between risk factors and clinical prognosis can be confirmed more accurately.

\section{Conclusion}

In summary, $\mathrm{ALT} \geq 200 \mathrm{U} / \mathrm{L}, \mathrm{PT} \geq 20 \mathrm{~s}$ and $\mathrm{ALB} \leq 30 \mathrm{~g} / \mathrm{L}$ are independent risk factors for the death, this implies that clinicians should carefully monitor these indexes for the development of AMP. Three organs damage could significantly increase mortality rate, especially liver. With the increase of liver damage, it may lead to coagulation and protein synthesis disorders. Therefore, hepatotoxic mushroom poisoning should be regarded as a medical emergency. However, the avoidance of re-exposure are sufficient treatment recommendations for mushroom poisoning.

\section{Conflict of interest}

The authors declare that there is no potential conflicts of interest.

\section{Acknowledgments}

We would like to thank the personnel of medical records department and in particular the department of nephrology, emergency, hemotology and infections for their kind cooperation.

\section{Refernces}

1 .

2. Schumacher T, Hoiland K. Mushroom poisoning caused by species of the genus Cortinarius Fries. Arch Toxicol 1983; 53 (2): 87-106.

3. James H. Diaz, MD, DrPH. Amatoxin-Containing Mushroom Poisonings: Species,Toxidromes, Treatments, and Outcomes. Wilderness Environ Med. 2018; 29 (1): 111-118.

4. Yilmaz I, Kaya E, Sinirlioglu ZA, ea tl. Clinical importance of toxin concentration in Amanita verna mushroom. Toxicon. 2014; 87: 68-75.

5. Block SS, Stephens RL, Barreto A,ea tl. Chemical identification of the Amanita toxin in mushrooms. Science; 1955;121 (3145): 505-506

6. Broussard, CN, Aggarwal, A, Lacey, SR, ea tl. Mushroom poisoning-from diarrhea to liver transplantation. Am J Gastroenterol. 2001;96 (11): 3195-3198.

7. Yardan T, Baydin A, Eden AO, et al. Wild mushroom poisonings in the Middle Black Sea region in Turkey: Analyses of 6 years. Hum Exp Toxicol. 2010; 29 (9): 767-771.

8. Karvellas CJ, Tillman H, Leung AA, et al. Acute liver injury and acute liver failure from mushroom poisoning in North America. Liver Int. 2016;36 (7): 1043-1050.

9. Dinis-Oliveira RJ, Soares M, Rocha-Pereira C, ea tl. Human and experimental toxicology of orellanine. Hum Exp Toxicol. 2016;35 (9): 1016-1029.

10. Eren SH, Demirel Y, Ugurlu S, ea tl. Mushroom poisoning: retrospective analysis of 294 cases. Clinics (Sao Paulo) . 2010;65 (5): 491-496.

11. Cervellin G, Comelli I, Rastelli G, ea tl. Epidemiology and clinics of mushroom poisoning in Northern Italy: A 21-year retrospective analysis. Hum Exp Toxicol.2017 Jan 1:960327117730882.

12. Lima AD, Costa Fortes R, Carvalho Garbi Novaes MR, ea tl. Poisonous mushrooms: a review of the most common intoxications. Nutr Hosp; 2012;27 (2): 402-408. 
13. Cevik AA, Unluoglu I. Factors Affecting Mortality and Complications in Mushroom Poisonings Over a 20 Year Period: Report from Central AnatoliaPeA Report from Central Anatolia. Turk J Emerg Med. 2016;14 (3): 104-110.

14. Yilmaz I, Kaya E, Sinirlioglu ZA, ea tl. Clinical importance of toxin concentration in Amanita verna mushroom. Toxicon. 2014;87:68-75.

15. Frank H, Zilker T, Kirchmair M, et al. Acute renal failure by ingestion of Cortinarius species confounded with psychoactive mushrooms: a case series and literature survey. Clin Nephrol; 2009; 71 (5): 557-562.

16. Cevik AA, Unluoglu I. Factors Affecting Mortality and Complications in Mushroom Poisonings Over a 20 Year Period: A Report from Central Anatolia.Turk J Emerg Med. 2016; 14 (3): 104-110.

17. Schmutz M, Carron PN, Yersin B. ea tl. Mushroom poisoning: a retrospective study concerning 11-years of admissions in a Swiss Emergency Department.Intern Emerg Med. 2018;13 (1): 59-67.

18. Danel VC, Saviuc PF, and Garon D. Main features of Cortinarius spp. poisoning: a literature review. Toxicon 2001; 39 (7): 1053-1060.

19. Short AI, Watling R, MacDonald MK, et al. Poisoning by Cortinarius speciosissimus. Lancet 1980; 2 (8201): 942-944.

20. Diaz JH.Syndromic diagnosis and management of confirmed mushroom poisoning[J].Crit Care Med,2005,33 (2): 427-436.

21. Erguven M, Yilmaz O, Deveci M, et al. Mushroom poisoning. Indian J Pediatr. 2007; 74 (9): 847-852.

22. Erden A, Esmeray K, Karagoz H, ea tl. Acute liver failure caused by mushroom poisoning: a case report and review of the literature. Int Med Case Rep J. 2013 , 22; 6: 85-90.

23. Schmutz M, Carron PN, Yersin B. ea tl. Mushroom poisoning: a retrospective study concerning 11-years of admissions in a Swiss Emergency Department. Intern Emerg Med. 2018; 13 (1): 59-67.
24. Jan M, Alina O, Marzena PO. ea tl. Early morphological and functional alterations in canine hepatocytes due to -amanitin, a major toxin of Amanita phalloides. Arch Toxicol (2009) 83: 55-60.

25. Santi L, Maggioli C, Mastroroberto M, ea tl. Acute liver failure caused by Amanita phalloides poisoning. Int J Hepatol. 2012; 2012: 487480.

26. Diaz JH. Amatoxin-Containing Mushroom Poisonings: Species, Toxidromes, Treatments, and Outcomes. Wilderness Environ Med. 2018;29 (1): 111-118.

27. Erenler AK, Doğan T, Koçak C, ea tl. Investigation of Toxic Effects of Mushroom Poisoning on the Cardiovascular System. Basic Clin Pharmacol Toxicol. $2016 ; 119$ (3): $317-321$.

28. Dadpour B, Tajoddini S, Rajabi M, ea tl. Mushroom Poisoning in the Northeast of Iran; a Retrospective 6-Year Epidemiologic Study. Emerg (Tehran) . 2017;5 (1): e23.

29. Wieland T. The toxic peptides from Amanita mushrooms. Int J Pept Protein Res. 1983;22 (3): 257-276.

30. Diaz JH. The syndromic diagnosis and management of confirmed mushroom poisonings. Crit Care Med. 2005;33 (2): 427-436.

31. Baumann K, Münter K, Faulstich H. Identification of structural features involved in binding of $\alpha$-amanitin to monoclonal antibody. Biochemistry. 1993;32 (15): 4043-4050.

32. Enjalbert F, Rapior S, Nouguier-Soulé J, ea tl. Treatment of Amatoxin Poisoning:20Year Retrospective Analysis. J Toxicol Clin Toxicol. 2002;40 (6): 715-757.

33. Trabulus S, Altiparmak MR.Clinical features and outcome of patients with amatoxin-containing mushroom poisoning.Clin Toxicol (Phila) 2011;49:303-310.

34. Ahishali E, Boynuegri B, Ozpolat E, et al. Approach to mushroom intoxication and treatment:can we decrease mortality? Clin Res Hepatol Gastroenterol. 2012;36 (2): $139-145$.

\section{Citation:}

Wen Li, Wu Weihua, Zhaolan Yu, Li Li, Linwang Gan, Santao Ou (2018) Analysis of Clinical Features and Risk Factors of Death in Patients Admitted to Hospital with Acute Mushroom Poisoning: A Retrospective Analysis of 315 Cases. J Clin Res Med Volume 1(2): 1-7. DOI: 10.31038/JCRM.1000108 